\title{
Short Circuit Study of Fixed Speed Wind Turbines with STATCOM in Distribution Networks
}

\author{
Muhammad Mat Naain \\ Brunel University London, U.K. \\ eepgmnm@brunel.ac.uk
}

\author{
Ahmed F. Zobaa \\ Brunel University London, U.K. \\ azobaa@ieee.org
}

\author{
Mohamed Darwish \\ Brunel University London, U.K. \\ mohamed.darwish@brunel.ac.uk
}

\begin{abstract}
The increased penetration of wind farm in distribution networks has brought changes in the performance of the whole system. Such disadvantages when connecting one of these distributed generation sources is reduced voltage and power stability of the AC network. This phenomena can cause the connected electricity consumers to suffer from disturbances. This paper investigates the use of a static synchronous compensator (STATCOM) to improve the short circuit current contribution in the network which will include balanced and unbalanced faults. The wind farm is equipped with fixed-speed wind turbines driving squirrel-cage induction generators. The IEEE 30-bus distribution test system is used to see the performance of the system under distribution level. Simulation studies are carried out in the DIgSILENT software.
\end{abstract}

Index Terms - Short circuit current, squirrel-cage induction generators, static synchronous compensator (STATCOM), wind farm, renewable energy

\section{INTRODUCTION}

Efforts have been made to generate electricity from renewable energy sources such as wind energy as a result of conventional energy source consumption and increasing environmental concern. Institutional and governmental support for wind energy sources has led to the fast development of wind power generation in recent years [1]. The continuous increase of wind farm capacity is likely to influence the operation of existing utility networks. The renewable sources may introduce various advantages such as unloading transmission system, reduce system losses, improving power quality and reliability [2]. The most crucial disadvantages of renewable energy integration are its impact on the voltage and power stability of the distributed network, which in turn may restrain the connection of the renewable energy to the network [3].

Wind turbine system technology is still the most promising renewable energy technology. Started with a few tens of $\mathrm{kW}$ power production per unit in the 1980 s, today multi-MW size wind turbines are being installed and they are very advanced power generators [4-5]. There is a widespread use of wind turbine in the distribution networks and also there are more and more wind power stations which are connected to the transmission networks. Denmark for example has more than $30 \%$ of wind energy in major areas of the country, and today $25 \%$ of all the electrical energy consumption is covered by wind energy. Initially, wind power did not have any serious impact on the power system control, but now due to its size, wind power has to play a much more active part in grid operation and control [6]. Wind turbines are consist of three parts which are the blades, generator and transformer that steps up the voltage into higher voltage to be connected into distribution network. Wind turbines are classified according to the characteristic of generator speed control and also the use of power electronic. Flexible AC transmission system FACTS devices such as Static Synchronous Compensator (STATCOM) to improve the short circuit level are studied. STATCOM is used to provide rapid and fast control of voltage during steady state and transient stability, which is possible due to the use of high power semiconductor switches (IGBT, IGCT) that produce high speed switching.

With the rapid increase in penetration of wind power in power systems, tripping of many wind turbines in a large wind farm during disturbance may influence the voltage stability [7]. Many researches have been done on using FACTS device to help the wind farm to achieve uninterrupted operation during grid fault. STATCOM is one of the devices that can provide controlled dynamic reactive power compensation. This paper present a short circuit study of the STATCOM application to improve the stability and performance of fixed speed wind farm connected to a distribution system during transient disturbances.

In this paper, the impact of placing the wind farm and STATCOM into the IEEE 30-bus system on the short circuit level will be examined. The impact of location of short circuit fault at certain buses will also be examined. The whole system will be simulated under three cases which are without wind farm, with wind farm and wind farm with STATCOM. The different type of faults involve include three-phase (3$\mathrm{ph}$ ), single-line to ground (LG), line to line (LL) and doubleline to ground (LLG). A detailed comparison for the fault level of all the cases will be presented and discussed. 


\section{SYSTEM MODEL WITH THE STATCOM}

The typical configuration of an individual fixed-speed wind turbine (FSWT) is shown in Fig. 1. It consists of a squirrel cage induction generator (SCIG) driven by a mechanical shaft system. The mechanical shaft will rotate when the rotor blade of the wind turbine rotate. The blade is forced to rotate when there is a wind. As the mechanical shaft rotate very slowly a gearbox is used to convert the low speed shaft to high speed SCIG rotor shaft since the SCIG rotor require revolution speed in the order of $1000 \mathrm{rpm}$.

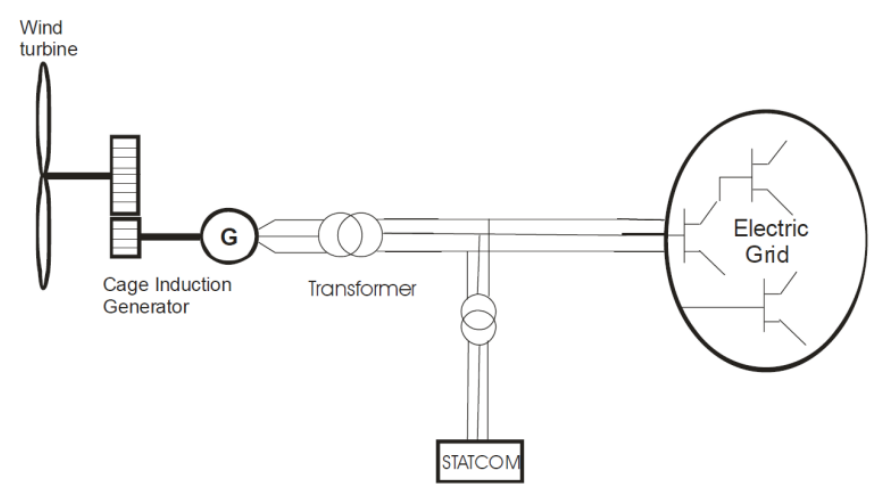

Fig. 1 : Schematic configuration of the system under study

Given the power coefficient $C_{P}$ the mechanical power that the wind turbine extracts from the wind is calculated by

$$
P_{m}=\frac{1}{2} \rho A_{r} v_{w}{ }^{3} C_{P}(\lambda, \beta)
$$

Where $\rho$ is the air density in $\mathrm{kg} / \mathrm{m}^{3}, A_{r}=\pi R^{2}$ in $m^{2}$ is the area swept by the rotor blades [8].

STATCOM is one of the devices in Flexible AC Transmission System (FACTS) family. Also called as advanced static VAR compensator [9], it is a voltage-sourced converter (VSC) that acts like a synchronous compensator. STATCOM allow continuous control of reactive power at high speed due to the use of forced-commutated converter using GTOs or IGBTs. STATCOM has the capability of controlling the amplitude and phase angle rapidly. It is coupled via transformer and a dc capacitor as shown in Fig. 2. The control system can be designed to maintain the magnitude of the bus voltage by changing the magnitude and phase shift of the VSC output voltage [10]. In this paper, STATCOM control system is modelled by DIgSILENT Simulation Language and is shown in Fig. 3.
The instantaneous three phase variables of the STATCOM can be described in state-space form by dq components using Park's transformation. The active and reactive powers injected into the network by the STATCOM are

$$
\begin{aligned}
& P=v_{d} i_{d}+v_{q} i_{q}=v_{d} i_{d} \\
& Q=-v_{d} i_{q}+v_{q} i_{q}=-v_{d} i_{q}
\end{aligned}
$$

Where $\mathrm{P}$ and $\mathrm{Q}$ are proportional to $i_{d}$ and $i_{q}[11-12]$.

The measured AC and DC voltages are sent to the PI controllers. The PI controllers are used to eliminate errors. Both PI controller produce the reference $d$ and $q$ currents for the built-in current controllers. The VSC used in DIgSILENT has a built-in current controller. The Phase Locked Loop (PLL) is used to transform the three phase currents from the grid to $\alpha \beta$ and from $\alpha \beta$ to dq coordinates. The d-component of current vector becomes active current component (d-current) and q-component becomes reactive current component (q-current).

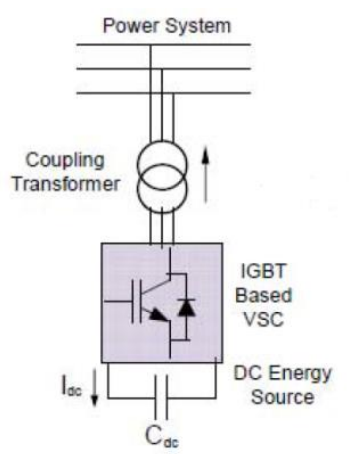

Fig. 2 : Equivalent circuit of STATCOM

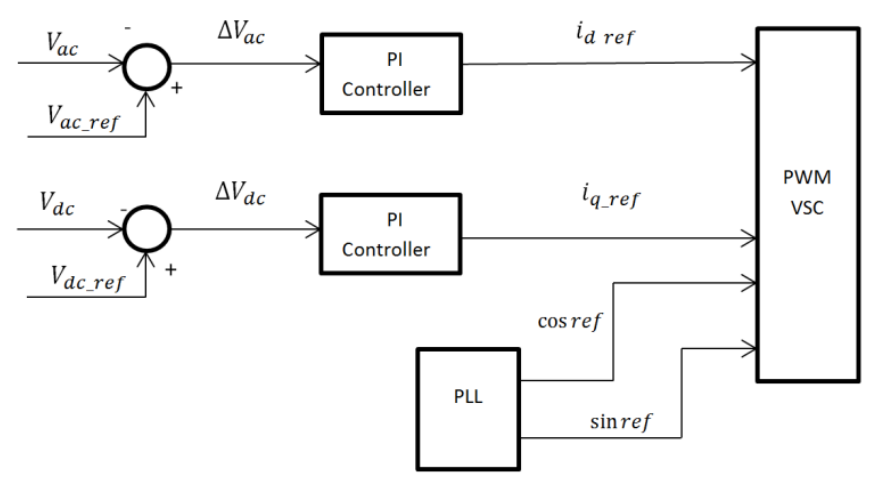

Fig. 3 : Structure of a STATCOM model as a voltage source converter 
III. SYSTEM UNDER STUDY

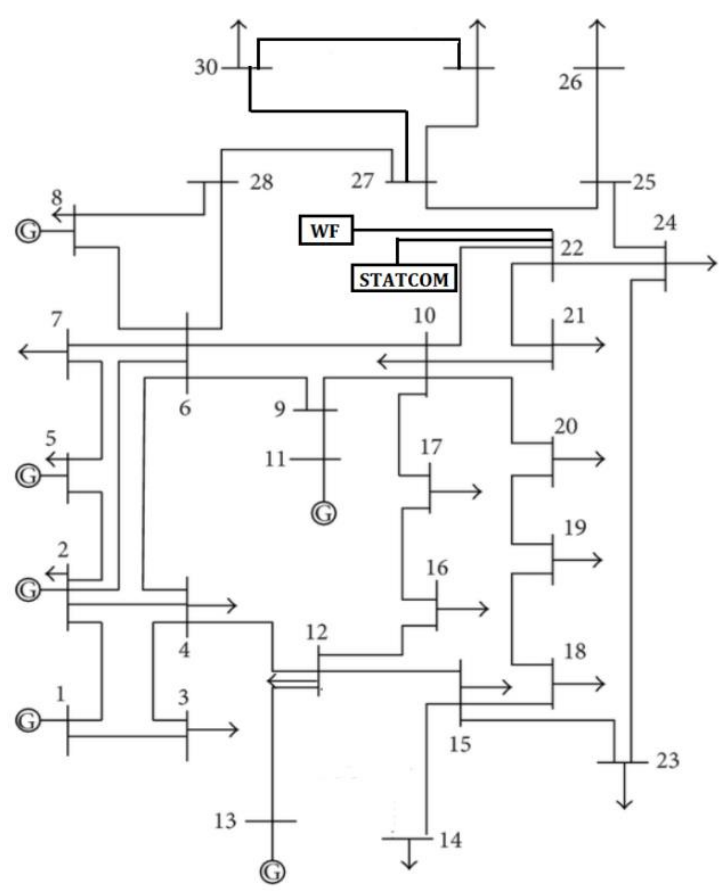

Fig. 4 : Single Line Diagram of the IEEE 30-Bus Distribution Test System

The short circuit analysis is performed on the IEEE 30-bus distribution test system using the DIgSILENT software as a simulation tool. The single line diagram of the simulated system is shown in Fig. 4. The data of the IEEE 30-bus can be found in reference [13]. The IEEE 30-bus system is consists of six generators and 21 loads. The wind farm is located at Bus 22. Bus 22 is also called as the Point of Connection (PCC) bus as this is the bus where the wind farm is connected to the distribution network. The STATCOM is also shunt connected to Bus 22 to provide dynamic reactive power compensation during disturbances and fault conditions [14].

Three different cases are applied to the study case to see the effect of wind farm and STATCOM on the short circuit level of the network as shown in Table 1. The simulation involves examination of four types of fault (3-phase, LG, LL and LLG) which happened at three different buses, Bus 18, Bus 22 and Bus 30. This is to see the effect of short circuit at bus close to the wind farm, bus far from the wind farm and also at the wind farm bus itself. The simulation results will be used to compare the short circuit current for each case and at different buses.
TABLE I

THREE DIFFERENT CASES APPLIED

\begin{tabular}{|c|c|}
\hline Case A & No wind farm \\
\hline Case B & 58MW wind farm at Bus 22 \\
\hline Case C & 58MW wind farm + 8 MVAR STATCOM at Bus 22 \\
\hline
\end{tabular}

\section{Simulated RESUlts}

TABLE II

SIMULATED RESULTS FOR SHORT CIRCUIT FAULT CURRENTS (KA)

\begin{tabular}{|c|c|c|c|}
\hline \multirow{2}{*}{ Location of Fault } & \multicolumn{3}{|c|}{ 3-Phase Fault } \\
\cline { 2 - 4 } & Case A & Case B & Case C \\
\hline Bus 18 & 4.24 & 4.32 & 4.35 \\
\hline Bus 22 & 12.80 & 19.09 & 22.79 \\
\hline Bus 30 & 3.34 & 3.39 & 3.41 \\
\hline & Single Line to Ground Fault \\
\hline & Case A & Case B & Case C \\
\hline Bus 18 & 4.27 & 4.32 & 4.35 \\
\hline Bus 22 & 13.46 & 17.45 & 21.16 \\
\hline Bus 30 & 3.36 & 3.38 & 3.41 \\
\hline & \multicolumn{3}{|c|}{ Line to Line Fault } \\
\hline & Case A & Case B & Case C \\
\hline Bus 18 & 3.68 & 3.74 & 3.77 \\
\hline Bus 22 & 11.09 & 16.54 & 19.73 \\
\hline Bus 30 & 2.89 & 2.93 & 2.95 \\
\hline & Double Line to Ground Fault \\
\hline & Case A & Case B & Case C \\
\hline Bus 18 & 4.30 & 4.37 & 4.41 \\
\hline Bus 22 & 13.29 & 18.26 & 21.99 \\
\hline Bus 30 & 3.39 & 3.43 & 3.46 \\
\hline
\end{tabular}

From Table 2 it can be seen that for all type of faults the highest short circuit current (SCC) happened at Bus 22, which is the wind farm bus. This is due to contribution of high SCC from the squirrel cage induction generator, which can be as high as 6 times the rated current [15]. The second highest SCC for all type of faults is at Bus 18 followed by Bus 30 . This is because Bus 18 is much closer to the wind farm compared to Bus 30, which is the farthest bus.

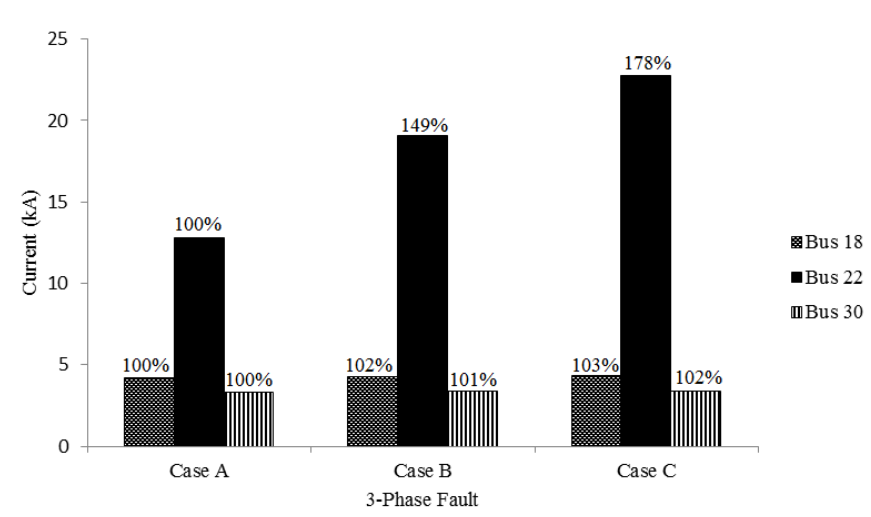

Fig. 5. Short Circuit Currents in different cases for 3-phase Faults 


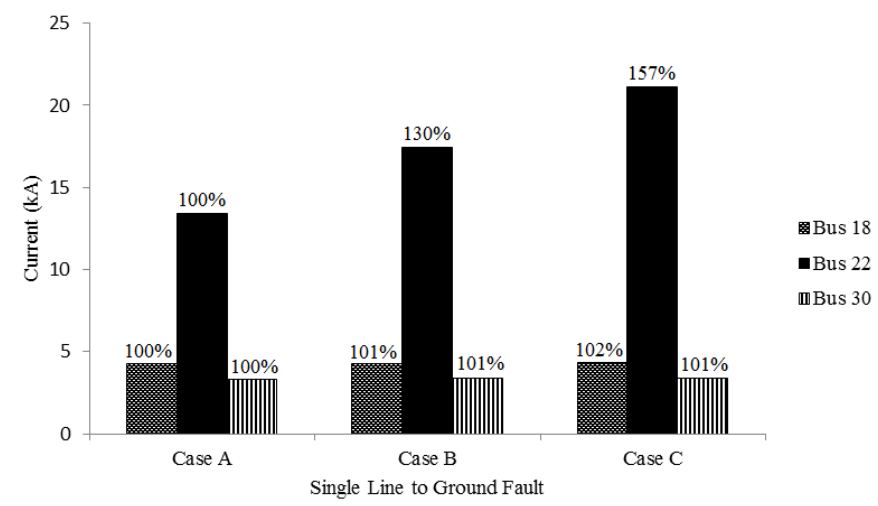

Fig. 6. Short Circuit Currents in different cases for Single Line to Ground Faults

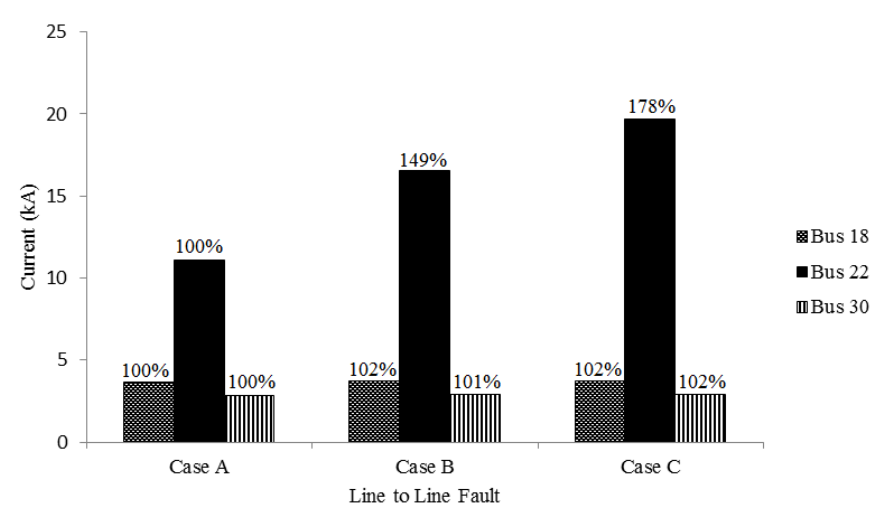

Fig. 7. Short Circuit Currents in different cases for Line to Line Faults

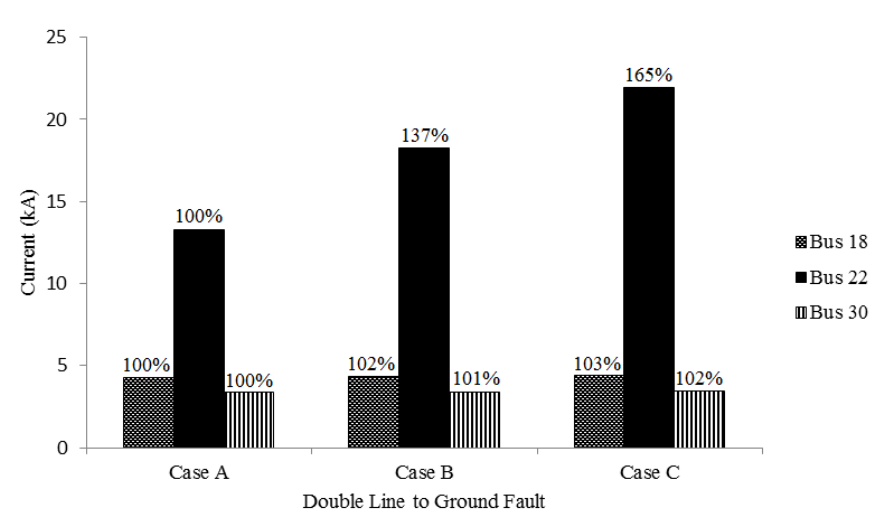

Fig. 8. Short Circuit Currents in different cases for Double Line to Ground Faults

Several charts has been plotted to show the percentage of increment of the SCC when the wind farm and STATCOM is introduced into the distribution network, as shown from Fig. 5-8. A 3-phase fault had the highest SCC especially at Bus 22 while a line to line fault had the lowest SCC value. From Fig. 5 which is the 3-phase fault, the SCC at Bus 22 increased significantly for Case B, which is the case for with wind farm. There is an increment of $49 \%$ of SCC from the initial value (Case A).
For Case C where there is a STATCOM, the SCC increased up to $78 \%$ from the value in Case A. In Fig. 6 for single line to ground fault, the SCC value at Bus 22 increased up to $30 \%$ and $57 \%$ for Case $\mathrm{B}$ and $\mathrm{C}$ respectively. Also the SCC at Bus 22 increased up to $49 \%$ and $78 \%$ for Case B and $\mathrm{C}$ respectively for line to line fault as shown in Fig. 7. The percentage of increment is the same as for the 3-phase fault. And for double line to ground fault as shown in Fig. 8, the SCC at Bus 22 increased to $37 \%$ in Case B while in Case C it increased up to $65 \%$ when compared to Case A. For all type of faults the SCC at Bus 18 and Bus 30 increased to a very small amount $(1-3 \%)$ when the wind farm and STATCOM is added to the system. From the chart it can be seen that the STATCOM make a significant contribution on the short circuit current at Bus 22 with percentage of increment of about $30 \%$ for all type of faults.

It is important to notice that the higher the fault current, the higher the bus voltage. When the bus voltage goes high during the fault this will result in improved voltage and power stability of the distribution network although the high fault current may have some negative impact to the circuit breakers [16].

\section{CONCLUSION}

This paper presented the impact of Type 1 WTG and STATCOM on the short circuit level of IEEE 30-bus distribution system by comparing three different cases, which are the distribution system without wind farm, with wind farm and wind farm with STATCOM. The 3-phase fault type had the most significant impact on Bus 22. For all type of faults, the highest SCC always occurred at wind farm bus which is Bus 22, followed by closer bus (Bus 18) and farthest bus (Bus 30). This is due to high contribution of SCC from the wind farm.

Finally it should be noticed that in associated with higher short circuit current the voltage stability and performance is likely to be improved [16]. If the STATCOM contributes a higher short circuit current, the voltage dip due to distant fault is reduced and the connected electricity consumers may suffer less from disturbances. Replacing the capacitor of the STATCOM with storage devices such as battery, supercapacitor, SMES etc. will be considered for future work to see the impact of these storage devices when being integrated into STATCOM on the short circuit contribution in the distribution network. 


\section{REFERENCES}

[1] Blaabjerg F, Chen Z, "Power electronics as an enabling technology for renewable energy integration," Journal of Power Electronics, vol. 3, pp. 81-89, 2003.

[2] F. M. Nuroglu and A. B. Arsoy, "Voltage Profile and short circuit analysis in distribution systems with DG," Electric Power Conference, EPEC 2008. IEEE Canada vol. 3, pp. 1-5, 2008.

[3] S. N. Afifi, H. Wang, G. A. Taylor, M. R. Irving, "Impact of DFIG Wind Turbines on Short Circuit Levels in Distribution Networks using ETAP," Power Engineering Conference (UPEC) $48^{\text {th }}$ International Universities, pp. 1-4, 2013.

[4] Z. Chen, J. M. Guerrero, F. Blaabjerg, "A review of the state of the art of power electronics for wind turbines," IEEE Trans. Power Electron. vol. 24, no. 8, pp. 1859-1875, August 2009.

[5] Z. Chen, S. B. Kjaer, F. Blaabjerg, "Power electronics as efficient interface in dispersed power generation systems," IEEE Trans. Power Electron., vol. 19, no. 5, pp. 1184-1194, Sept. 2004.

[6] Marco Liserre, Ke Ma, F. Blaabjerg, "Power Electronic Converters for Wind Turbine Systems," IEEE Transactions on Industry Applications, vol. 48, no. 2, pp. 708-719, March/April 2012.

[7] Tarek Medalel Masaud, P. K. Sen, "Study of the Implementation of STATCOM on DFIG-Based Wind Farm Connected to a Power System", Innovative Smart Grid Technologies (ISGT), pp 1-7, Jan 2012.

[8] Wei Qiao, Harley R. G., "Power Quality and Dynamic Performance Improvement of Wind Farms Using a STATCOM," Power Electronics Specialists Conference, pp. 1832-1838, 2007.

[9] Muhammad H. Rashid, "Power Electronics Devices, Circuits and Applications", Fourth Edition, Pearson Education Limited , 2014

[10] N. Mithulananthan, Claudio A. Canizares, "Comparison of PSS, SVC and STATCOM controllers for damping power system oscillation", IEEE Trans. Power Systems, October 2002.

[11] P. Garcia-Gonzalez, A. Garcia C., "Control system for a PWM-based STATCOM", Universidad Pontificia Comillas de Madrid, Spain.

[12] Marta Molinas, Birgitte Bak-Jensen, "Wind Farms in Weak Grids Compensated with STATCOM", Nordic PhD course on Wind Power, June 2005.

[13] E. D. Tuglie, S. M. Lannone, F. Torelli, "A coherency-based method to increase dynamic security in power systems", Electric Power Systems Research, vol. 78, no. 8, pp. 1425-1436, 2008.

[14] Guizhen Tian, Shengtie Wang, Guangchen Liu, "Power quality and transient stability improvement of wind farm with fixed-speed induction generators using a STATCOM," Power System Technology (POWERCON), pp. 1-6, Oct. 2010.

[15] E. Muljadi, V. Gevorgian, N. Samaan, J. Li, S. Pasupulati, "Short Circuit Current Contribution for Different Wind Turbine Generator Types," IEEE Power and Energy Society, July 2012.

[16] Y. Jiang-Hafner, M. Hyttinen, B. Paajarvi, "On the Short Circuit Current Contribution of HVDC Light," Transmission and Distribution Conference and Exhibition, vol. 3, pp. 1926-1932, 2002. 